\title{
Serotonergic Mechanisms in Anxiolytic Effect of Tandospirone in the Vogel Conflict Test
}

\author{
Hiroshi Shimizu, Tohru Tatsuno, Hiroyasu Tanaka, Akira Hirose, Yoshino Araki and Mitsutaka Nakamura \\ Research Laboratories, Sumitomo Pharmaceuticals Co., Ltd., 3-1-98, Kasugadenaka, Konohana-ku, Osaka 554, Japan \\ Received October 5, 1991 Accepted February 14, 1992
}

\begin{abstract}
To clarify which 5- $\mathrm{HT}_{1 \mathrm{~A}}$ receptors, autoreceptors located in the raphe nuclei or postsynaptic receptors in the forebrain arcas receiving a 5-HT input, mediate the anticonflict action of tandospirone (a $5-\mathrm{HT}_{1 \mathrm{~A}}$ receptor-related anxiolytics), the behavioral effects of tandospirone were studied in 5,7-dihydroxytryptamine (5,7-DHT) treated rats. By measuring both monoamines and their metabolite levels and densities of $\left[{ }^{3} \mathrm{H}\right] 8-\mathrm{OH}$-DPAT binding in 5,7-DHT-treated rat brain, we confirmed that pretreatment with 5,7-DHT destroyed 5-HT neurons selectively without affecting postsynaptic 5-HT $1 \mathrm{~A}$ receptors located on the postsynaptic neurons. This selective destruction produced no significant changes in the drinking behavior of rats in either punished or unpunished sessions of the Vogel conflict test. Furthermore, this destruction altered neither the effect of tandospirone on punished responding in this procedure nor the potency of tandospirone to induce a flat body posture in rats, which is known as the "serotonin behavioral syndrome". These results suggested that the anticonflict action of tandospirone may be produced, at least in part, by binding to postsynaptic $5-\mathrm{HT}_{1 \mathrm{~A}}$ receptors and activating them as agonists, and not to $5-\mathrm{HT}_{1 \mathrm{~A}}$ autoreceptors located on the cell bodies of 5-HT neurons.
\end{abstract}

Keywords: Tandosprirone, Anxiolytics, 5- $\mathrm{HT}_{1 \mathrm{~A}}$ receptors, 5,7-Dihydroxytryptamine, Anticonflict action

The serotonin (5-HT) system has long been implicated in the control of anxiety. Benzodiazepines, predominantly used in the therapy of anxiety, for examplc, are known to reduce 5-HT turnover and decrease the activity of the central 5-HT neurons (1). The role of 5HT in anxicty, however, remains to be elucidated, because there is still controversy regarding the role of 5HT in animal models to predict the anxiolytic activity in man. Recent radioligand binding studies revealed four types of 5-HT receptors in the mammalian brain designated as $5-\mathrm{HT}_{1}, 5-\mathrm{HT}_{2}, 5-\mathrm{HT}_{3}$ and $5-\mathrm{HT}_{4}$ receptors $(2$, $3)$. The $5-\mathrm{HT}_{1}$ receptors can be further divided into four distinct subtypes which are presently termed 5$\mathrm{HT}_{1 \mathrm{~A}}, 5-\mathrm{HT}_{1 \mathrm{~B}}, 5-\mathrm{HT}_{1 \mathrm{C}}$ and $5-\mathrm{HT}_{1 \mathrm{D}}$ receptors $(4,5)$. Therefore, previous reports studying the role of 5-HT in anxicty should be reviewed again considering the effects on these 5-HT receptor subtypes.

Tandospirone (3a $\alpha, 4 \beta, 7 \beta, 7 \mathrm{a} \alpha$-hexahydro-2-(4-(4-(2pyrimidinyl )-1-piperazinyl )-butyl )-4, 7-methano- $1 \mathrm{H}$-isoindole-1,3 $(2 \mathrm{H})$ dione dihydrogen citrate) is a non-benzodiazepine compound possessing both potent anxio- lytic properties in animal models (6) and a high potency to bind selectively to $5-\mathrm{HT}_{1 \mathrm{~A}}$ receptors $(7,8)$. Therefore, this compound may be a useful tool for basic research on the rolc of 5-HT in anxiety. We have found that spiroperidol (a nonselective 5-HT $\mathrm{T}_{1 \mathrm{~A}}$ antagonist), but not haloperidol (a $\mathrm{D}_{2}$-antagonist) or ketanserin (a $5-\mathrm{HT}_{2}$ antagonist), inhibits significantly the anticonflict action of tandospirone in Vogel's conflict test $(\mathrm{H}$. Shimizu et al., unpublished data). Therefore, it is suggested that the agonist action of tandospirone on 5$\mathrm{HT}_{1 \mathrm{~A}}$ receptors may produce its anxiolytic activity. It is, however, well-known that there is a functional difference between $5-\mathrm{HT}_{1 \mathrm{~A}}$ receptors in the brain areas receiving a serotonergic input from the raphe nuclei and those in the raphe nuclei (9). Namely, the former are postsynaptic receptors located on the postsynaptic neurons, and the latter arc autoreceptors located on the cell bodies and dendrites (but not presynaptic terminals) of 5-HT neurons. A function of the autoreceptors is to trigger feedback mechanisms which exert a negative influence on the neuron impulse flow and the 5-HT 
release process in these neurons (10). Tandospirone binds to both postsynaptic receptors and somatodendritic autoreceptors in the same manner $(11,12)$. Thus, to clarify which receptors mediate the anxiolytic activity of tandospirone, we studied the behavioral effects of tandospirone in 5,7-DHT-treated rats in the present report.

\section{MATERIALS AND METHODS}

Male Sprague-Dawley rats $(180-200 \mathrm{~g})$ were used in all experiments. These subjects were housed four per cage in a temperature and humidity-controlled room with a 12-hr day-night cycle (illumination from 08002000 hours) and received food and water ad libitum except when indicated. Tandospirone dissolved in saline or saline alone was administered in volumes of $5 \mathrm{ml} / \mathrm{kg}$ in rats.

\section{5,7-DHT treatment}

Rats were pretreated with desipramine $(25 \mathrm{mg} / \mathrm{kg}$, i.p.) to protect against the destruction of norepinephrine neurons (13). Fifteen minutes following the pretreatment, the rats were anesthetized with pentobarbital $(48 \mathrm{mg} / \mathrm{kg}$, i.p.) and placed in a stereotaxic frame. Fifteen minutes following the pentobarbital administration, $100 \mu \mathrm{g}$ of 5,7-dihydroxytryptamine (5,7-DHT), a selective neurotoxine of 5-HT neurons (14), dissolved in $20 \mu \mathrm{l}$ of saline, or saline alone for the control rats was injected into the right lateral ventricle. Rats were used, following 15 days and 16 days in their home cages, for behavioral tests (conflict and 5-HT syndrome) and for biochemical confirmation of the lesion (quantitative autoradiography and measurements of monoamines and their metabolite levels), respectively.

\section{Monoamines and their metabolite levels}

Rats were sacrificed by decapitation, and then the brains were quickly removed, rinsed in ice-cold saline, and dissected into 5 regions: cerebral cortex, hippocampus, striatum, thalamus and hypothalamus, and mesencephalon. Immediately, the tissues were weighed, frozen in ethanol-dry ice, and stored at $-24^{\circ} \mathrm{C}$ until assayed (within a week). Monoamines and their metabolites were analyzed by the method described in our previous report (15) using high performance liquid chromatography with electrochemical detection (HPLCECD). The amount of each compound in a sample was determined by measuring peak heights and comparing them with the known standards. The data from the tissue samples were expressed in nanograms per grams of tissue wet weight.

\section{$I^{3} H / 8-O H-D P A T$ binding}

Rats were sacrificed by decapitation, and the brains were quickly removed, rinsed in ice-cold saline, and frozen in ethanol-dry ice. Twenty-micron-thick tissue sections were cut at $-15^{\circ} \mathrm{C}$ using a microtome cryostat, thaw-mounted onto gclatine-coated glass slides, and stored at $-25^{\circ} \mathrm{C}$ until used (for less than 2 wocks). Sections were labeled in vitro according to the procedure of Verge et al. (16). In brief, tissue sections were preincubated at $25^{\circ} \mathrm{C}$ for $30 \mathrm{~min}$ in $0.17 \mathrm{M}$ Tris-HCl buffer $(\mathrm{pH} 7.4)$. Slides were then incubated at $25^{\circ} \mathrm{C}$ for $60 \mathrm{~min}$ in the same buffer, containing $\left[{ }^{3} \mathrm{H}\right] 8$-hydroxy-2(di- $n$-propylamino) tetralin $\left(\left[{ }^{3} \mathrm{H}\right] 8-\mathrm{OH}-\mathrm{DPAT}, 2 \mathrm{nM}\right)$, $\mathrm{CaCl}_{2}(4 \mathrm{mM})$, and clomipramine $(0.5 \mu \mathrm{M})$, which is a 5 -HT reuptake inhibitor. After incubation, washing (2 $\times 5 \mathrm{~min}$ in ice-cold preincubation buffer and quick dipping in ice-cold distilled water), and drying with cold air, the slides were put in close contact with a sheet of tritium-sensitive film (Sakura, Japan) and allowed to expose in the dark at $4^{\circ} \mathrm{C}$ for 3 weeks. The nonspecific binding was determined by adding unlabeled $8-\mathrm{OH}-$ DPAT $(1 \mu \mathrm{M})$ to the incubations. Analysis of the autoradiograms was performed with an image analysis system (Unigraphy UHG-101, Unique Medical, Japan) using a densitometry program. This densitometry program converts optical densities to $\mathrm{fmol} / \mathrm{mg}$ protein using tritium micro-scales (Amersham, U.K.) co-exposed with the tissue sections. The protein concentration was measured by the method of Lowry et al. (17).

\section{Conflict test}

A modification of the method of Vogel et al. (18) was used.

Effect of 5,7-DHT treatment: Both control and 5,7DHT-treated rats were deprived of water for a $24-\mathrm{hr}$ period prior to the first training session (unpunished session), which always started at between 1000 and 1200 hours. In the session, each animal was placed in a plexiglass conflict test box $(38 \times 38 \times 20 \mathrm{~cm})$. A water bottle with a stainless steel spout was fitted onto the outside of one side so that the spout extended $1 \mathrm{~cm}$ into the box at a height of $2 \mathrm{~cm}$ above the base level. The rat was allowed to explore until it discovered the drinking spout and began to drink, and then the number of licks from the spout within a 3-min period (unpunished responding) was counted. The rats were successively deprived of water until the second session. Twenty-four hours following the unpunished session, which meant 48 $\mathrm{hr}$ after the introduction of the water-deprivation, each rat was again placed in the test box. The second session (pre-drug punished session) also lasted for a 3-min period and started automatically when the rat completed 20 licks and received the first mild electric shock 
$(0.35 \mathrm{~mA}, 0.5 \mathrm{sec})$ which was delivered through the spout and the grid floor. Following every 20 unpunished licks, subsequent licking was punished. The number of shocks received within 3 min (punished responding) was counted.

Effect of tandospirone: Only rats displaying suppressed licking (less than 260 licks) due to punishment during the pre-drug punished session in comparison with the unpunished session were included in the study. The rats were successively deprived of water until the next session. Both control rats and 5,7-DHT-treated rats received either tandospirone $(0.1,0.3$, and $1.0 \mathrm{mg} / \mathrm{kg}$, s.c.) or saline $2 \mathrm{hr}$ after the pre-drug punished session. One hour after the administration, the 3-min punished session (post-drug punished session) was repeated. The number of shocks received in the post-drug punished session was measured. Each animal was used only once.

\section{5-HT syndrome}

Rats were placed singly in a clear plastic cage $(50 \times$ $25 \times 20 \mathrm{~cm})$. Five minutes later, the rat received tandospirone $(0.1,0.3$ and $1.0 \mathrm{mg} / \mathrm{kg}$, s.c.) or saline. Observation sessions of a 15 -sec duration began $3 \mathrm{~min}$ later and were repeated every $3 \mathrm{~min}$ over a period of 30 min. Flat body posture was scored using a ranked intensity scale: $0=$ absent, $1=$ equivocal, $2=$ present and $3=$ intense. Each score was summed up over the 10 observation periods.

\section{Drugs}

The following drugs were used: Tandospirone citrate, and 8-OH-DPAT $\mathrm{HBr}$ (Sumitomo Pharmaceuticals Co. Ltd.); 5,7-DHT creatinine sulfate, L-NE bitartrate, DA $\mathrm{HCl}$, and HVA (Sigma, U.S.A.); DL-MHPG piperazine, DOPAC, 5-HIAA, 1-octane and sulfonic acid $\mathrm{Na}$ (Aldrich, U.S.A.); 5-HT creatinine sulfate (Merck, G.F.R.); DL-isoproterenol $\mathrm{HCl}$ (Nacalai Tesque, Japan $)$; and $\left[{ }^{3} \mathrm{H}\right] 8-\mathrm{OH}-\mathrm{DPAT}(183 \mathrm{Ci} / \mathrm{mmol}$, Amersham, U.K.).

\section{Statistical analyses}

Data were analyzed by two-way analysis of variance (ANOVA $2 \times 2$ ) followed by Tukey's test. Biochemical data were analysed by Student's $t$-test.

\section{RESULTS}

\section{Monoamines and their metabolite levels}

Table 1 shows the extent of regional depletions of central monoamines and their metabolites, 16 days following the administration of 5,7-DHT. In these subjects, pretreatment with 5,7-DHT significantly decreased the concentrations of 5-HT and its metabolite (5-HIAA) in all brain areas examined, when compared to the saline-treated (control) rats. Particularly in the hippocampus, the levels of 5-HT and 5-HIAA in the 5,7-DHT-treated rats decreased markedly to $6 \%$ and $10 \%$ of the control rats, respectively. In contrast, the concentrations of NE, DA and its metabolites (DOPAC and HVA) were not significantly altered in any area of the brain. These results show a specific and extensive degeneration of serotonergic terminals in the

Table 1. Effects of the pretreatment with 5,7-DHT on the concentrations of monoamines and their metabolites in various brain regions of rats

\begin{tabular}{|c|c|c|c|c|c|c|c|}
\hline \multirow[b]{2}{*}{ Region } & \multirow[b]{2}{*}{ Treatment } & \multicolumn{6}{|c|}{ Concentrations of the monoamines and their metabolites } \\
\hline & & NE & $\mathrm{DA}$ & DOPAC & HVA & 5-HT & 5-HIAA \\
\hline \multirow[t]{2}{*}{ Cerebral cortex } & Control & $347 \pm 21$ & $455 \pm 55$ & $99 \pm 13$ & $66 \pm 6$ & $618 \pm 13$ & $282 \pm 9$ \\
\hline & 5,7-DHT & $337 \pm 22$ & $449 \pm 53$ & $98 \pm 12$ & $58 \pm 5$ & $233 \pm 60^{* *}$ & $102 \pm 22^{* *}$ \\
\hline \multirow[t]{2}{*}{ Hippocampus } & Control & $392 \pm 16$ & $37 \pm$ & $8 \pm 3$ & $10 \pm 1$ & $437+25$ & $329 \pm 23$ \\
\hline & 5.7-DHT & $319 \pm 14$ & $22 \pm$ & $9 \pm 1$ & $10 \pm 1$ & $26 \pm 7^{* *}$ & $34 \pm 8^{* *}$ \\
\hline \multirow[t]{2}{*}{ Striatum } & Control & $216 \pm 41$ & $9070 \pm 510$ & $1310 \pm 66$ & $698 \pm 44$ & $446 \pm 23$ & $413 \pm 12$ \\
\hline & 5,7-DHT & $145 \pm 10$ & $8070 \pm 186$ & $1270 \pm 44$ & $591 \pm 36$ & $242 \pm 61^{*}$ & $256 \pm 52^{*}$ \\
\hline Thalamus + & Control & $845 \pm 26$ & $247 \pm 10$ & $53 \pm 4$ & $29 \pm 3$ & $539 \pm 15$ & $398 \pm 12$ \\
\hline Hypothalamus & 5,7-DHT & $856 \pm 50$ & $225 \pm 21$ & $50 \pm 5$ & $25+5$ & $267 \pm 32^{* *}$ & $192 \pm 27^{* *}$ \\
\hline \multirow[t]{2}{*}{ Mesencephalon } & Control & $584 \pm 13$ & $75 \pm 4$ & $27 \pm$ & $20 \pm 3$ & $589 \pm 10$ & $483 \pm 17$ \\
\hline & 5,7-DHT & $558 \pm 20$ & $82 \pm 20$ & $28 \pm 3$ & $17 \pm 3$ & $331 \pm 53^{* *}$ & $240 \pm 59^{* *}$ \\
\hline
\end{tabular}

Data are expressed in $\mathrm{ng} / \mathrm{g}$ wet tissue; Each value represents the mean \pm S.E.M. obtained from five animals. ${ }^{*} \mathrm{P}<0.05,{ }^{* *} \mathrm{P}<0.01$, compared to the corresponding control group (Student's $t$-test). 


\section{5,7-DHT-treated rats.}

\section{$\left.{ }^{3} H\right] 8-O H-D P A T$ binding}

Figure 1 shows autoradiograms of specific $\left[{ }^{3} \mathrm{H}\right] 8-\mathrm{OH}-$ DPAT binding to the hippocampus (A) and the dorsal raphe nucleus $(B)$ in a control rat and a 5,7-DHT treated rat. Table 2 shows specific $\left[{ }^{3} \mathrm{H}\right] 8-\mathrm{OH}-\mathrm{DPAT}$ binding ( $\mathrm{fmol} / \mathrm{mg}$ protcin) in various brain areas calculated from autoradiographic films. In control animals, $\left[{ }^{3} \mathrm{H}\right] 8$ OH-DPAT binding sites were particularly abundant in the hippocampus, entorhinal cortex, interpeduncular nucleus, lateral septum and dorsal raphe nucleus. No $\left[{ }^{3} \mathrm{H}\right] 8-\mathrm{OH}-\mathrm{DPAT}$ binding sites could be detected in the caudate putamen, substantia nigra and nucleus accumbens. Also, low to moderate densities of binding sites were found in the other examined structures (Table 2). This regional distribution of $\left[{ }^{3} \mathrm{H}\right] 8-\mathrm{OH}-\mathrm{DPAT}$ binding sites was in agreement with those of $5-\mathrm{HT}_{1 \mathrm{~A}}$ receptors in a previous report (17). Pretreatment with 5,7-DHT significantly reduced $\left[{ }^{3} \mathrm{H}\right] 8-\mathrm{OH}-\mathrm{DPAT}$ binding density in the dorsal raphe nucleus to $63 \%$ of the control (Fig. 1B, Table 2). This shows that 5- $\mathrm{HT}_{1 \wedge}$ autoreceptors were reduced by either a direct neurotoxic effect of 5,7DHT on serotonergic cell bodies located in the dorsal raphe or a retrograde degeneration of the lesioned 5HT neurons. In contrast, no significant difference was obscrved in the binding densitics in the hippocampus (Fig. 1A) nor in any area of the brain but the dorsal raphe nucleus (Table 2).

\section{Conflict test}

Fourteen days after 5,7-DHT treatment, there was no significant difference in spontaneous drinking behaviors between the control rats and the 5,7-DHT-treated rats.

Control

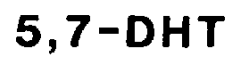

(A)

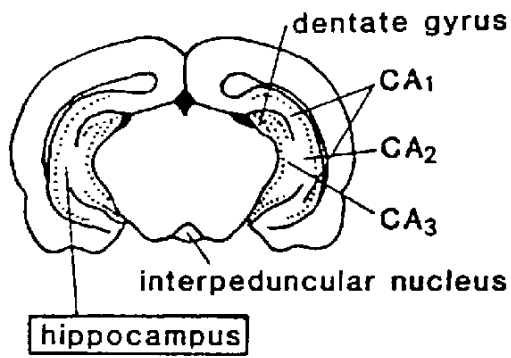

(B)

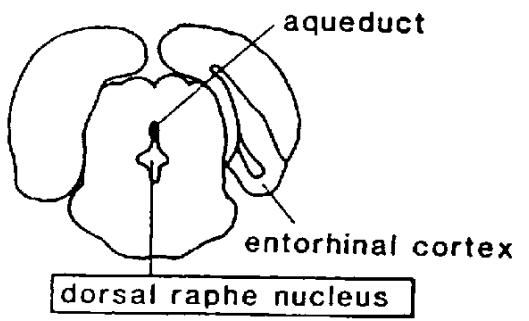

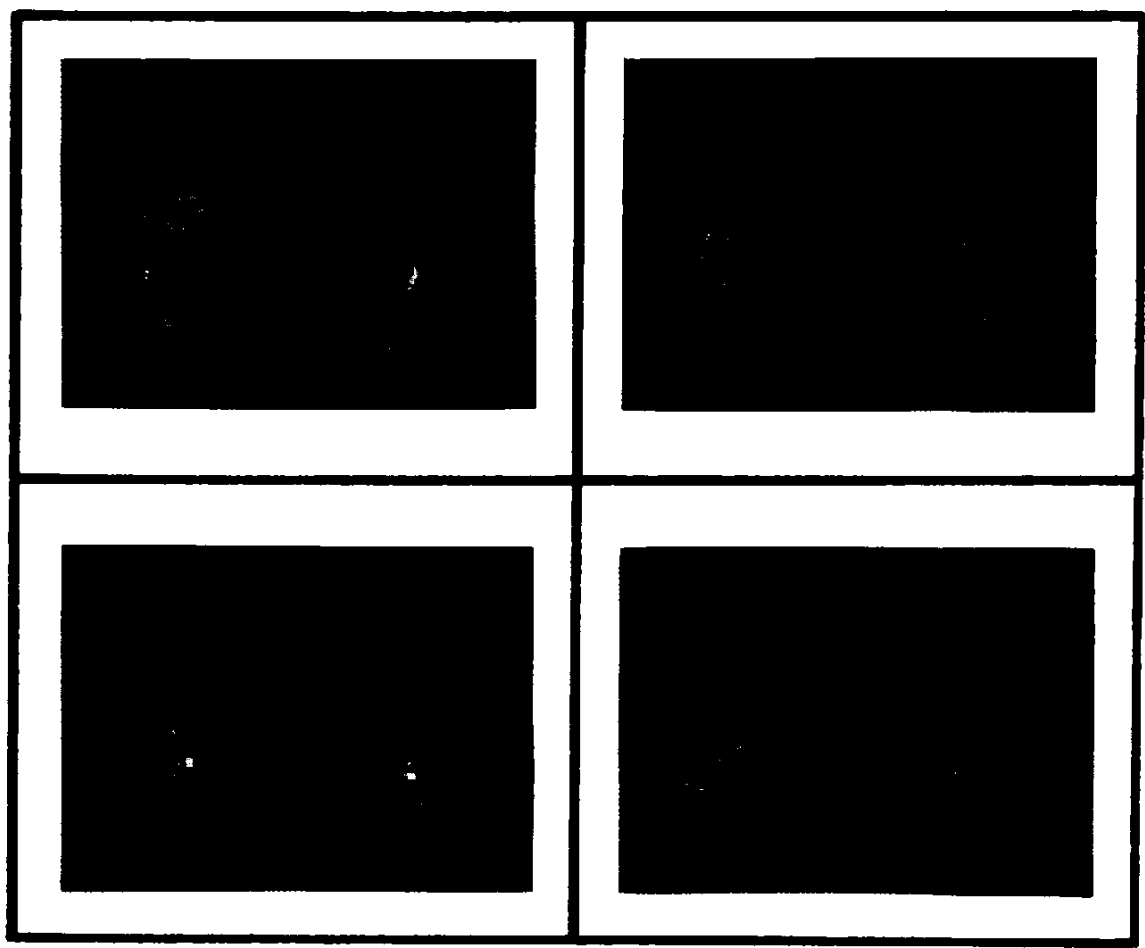

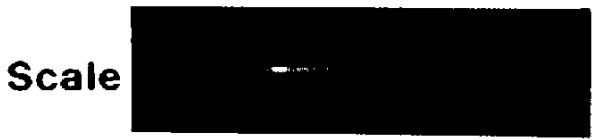

Fig. 1. Autoradiograms of $\left[{ }^{3} \mathrm{H}\right] 8-\mathrm{OH}-\mathrm{DPAT}$ binding to the hippocampus (A) and the dorsal raphe nucleus. (B) of a control rat and a 5,7-DHT-treated rat. 5,7-DHT was administered by intracerebroventricular injection and animals were sacrificed 16 days later. Coronal sections were taken at $(A)=-5.70 \mathrm{~mm},(B)=-7.80 \mathrm{~mm}$ from the bregma, according to the stereotaxic atlas of Paxinos and Watson (39), and they were then incubated with $2 \mathrm{nM}\left[{ }^{3} \mathrm{H}\right] 8-\mathrm{OH}-\mathrm{DPAT}$. Similar results were obtained in five rats in each group. The color scale indicates decreasing binding densities from red to purple. 
Table 2. Effects of the pretreatment with 5,7-DHT on 5-HT $1 \wedge$ receptors labeled with $\left[{ }^{3} \mathrm{H}\right] 8$-OH-DPAT in various brain regions

\begin{tabular}{|c|c|c|}
\hline \multirow[b]{2}{*}{ Brain structurc } & \multicolumn{2}{|c|}{ Specific binding (fmol/mg tissue) } \\
\hline & control & 5.7-DHT \\
\hline \multicolumn{3}{|l|}{ Posterior hippocampus } \\
\hline Dentate gyrus & $147 \pm 5$ & $141 \pm 6$ \\
\hline CA field & $131 \pm 5$ & $135 \pm 5$ \\
\hline Entorhinal cortex & $124 \pm 5$ & $119 \pm 4$ \\
\hline \multicolumn{3}{|l|}{ Anterior hippocampus } \\
\hline Dentate gyrus & $115 \pm 4$ & $113 \pm 4$ \\
\hline Interpeduncular nucleus & $115 \pm 7$ & $114 \pm 2$ \\
\hline Lateral septum & $107 \pm 3$ & $114 \pm 1$ \\
\hline Dorsal raphe nucleus & $100 \pm 9$ & $62 \pm 6^{* *}$ \\
\hline \multicolumn{3}{|l|}{ Amygdala } \\
\hline Cortical nucleus & $71 \pm 5$ & $63 \pm 4$ \\
\hline Central nucleus & $35 \pm 1$ & $37 \pm 2$ \\
\hline Ventromedial hypothalamic nucleus & $49 \pm 2$ & $50 \pm 7$ \\
\hline Frontal cortex & $32 \pm 2$ & $39 \pm 2$ \\
\hline Median raphe nucleus & $21 \pm 4$ & $16 \pm 3$ \\
\hline Caudate putamen & n.d. & n.d. \\
\hline Substantia nigra & n.d. & n.d. \\
\hline Nucleus accumbens & n.d. & n.d. \\
\hline
\end{tabular}

Data were calculated from optical densities of the autoradiographic films; Each value represents the mean \pm S.E.M. obtained from five animals (3-13 sections). Nonspecific binding was subtracted from all density readings. ${ }^{* *} \mathbf{P}<0.01$, compared to the corresponding control group (Student's $t$-test), n.d.: not detectable.

The number of licks was $26.4 \pm 1.0$ and $26.6 \pm 1.0$ (means \pm S.E.M.), respectively (Fig. 2). Likewise, in the punished sessions, the number of licks by the $5,7-$ DHT-treated rats $(4.1 \pm 0.5)$ was not significantly different from that of the control rats $(5.8 \pm 0.8)$.

Figure 3 shows the effect of tandospirone on the punished responding of the control and 5,7-DHTtreated rats 15 days after saline or 5,7-DHT-treatment. Tandospirone significantly increased the punished responding of the 5,7-DHT-treated rats as well as that of the control rats. The minimum effective dose of tandospirone in this test was $1.0 \mathrm{mg} / \mathrm{kg}$, s.c. in both the control and the 5,7-DHT-treated rats.

\section{5-HT syndrome}

Tandospirone induced a flat body posture, one of the components of the "5-HT behavioral syndrome", in a dose-dependent manner in both the control and 5,7DHT-treated rats. Figure 4 shows the intensities of this behavior induced by various doses of tandospirone in the control and the 5,7-DHT-treated rats. No significant difference in the potency of tandospirone between the two groups was observed.

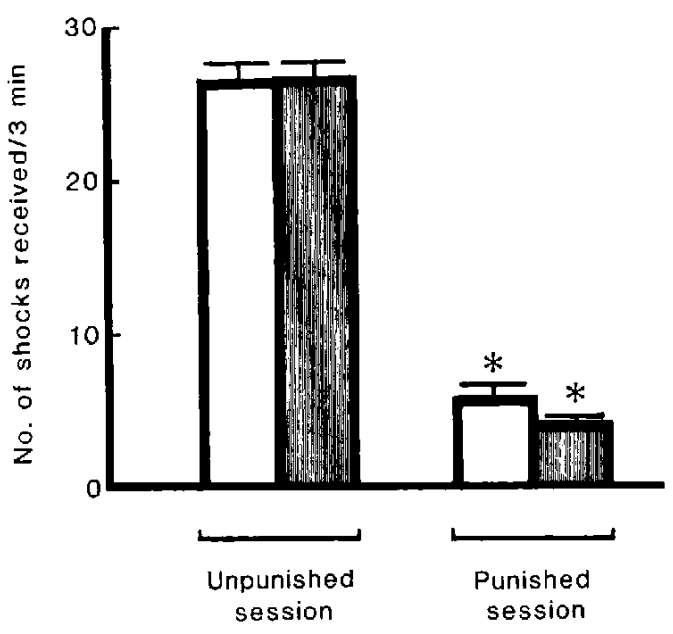

Fig. 2. The effects of the 5,7-DHT treatment on the drinking behavior of the rats in punished and unpunished sessions of the Vogel conflict test. The number of shocks received in the unpunished session and the punished session was measured 14 days and 15 days following the intracerebroventricular administration of 5,7-DHT, respectively. Each value represents the mean \pm S.E.M. obtained from 37 control rats and 48 5,7-DHT-treated rats. ${ }^{*} \mathrm{P}<0.01$, compared to the corresponding unpunished responding (Tukey's test). ( $\square$ ) control group, (1i) 5,7-DHT-treated group. 


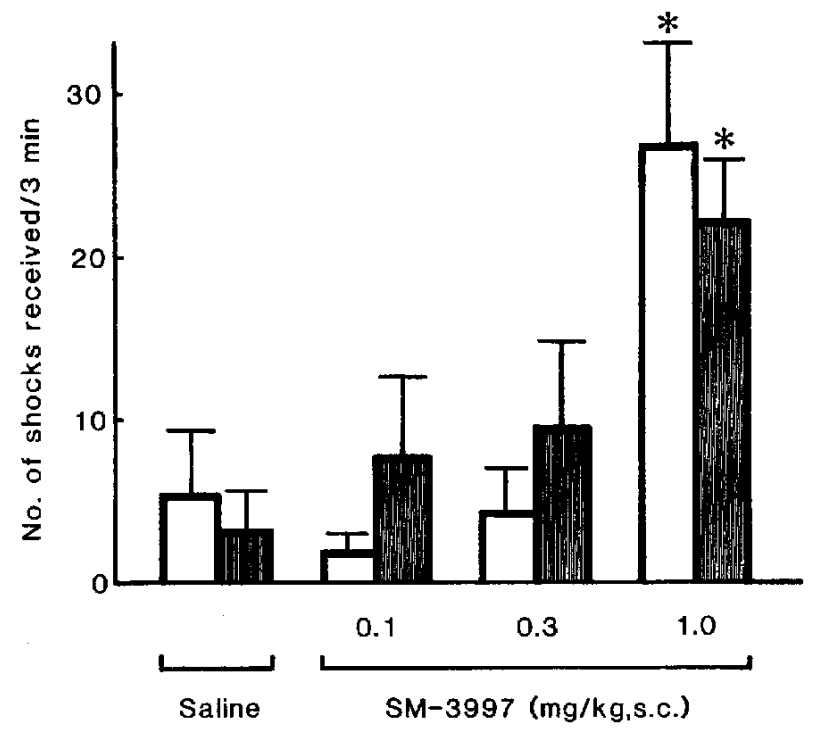

Fig. 3. The effects of the treatment with 5,7-DHT on the anticonflict action of tandospirone in the Vogel conflict test. Tandospirone was adminisered 15 days following the intracerebroventricular injection of 5,7-DHT. The number of shocks received in the punished session was measured $1 \mathrm{hr}$ following the tandospirone administration. Each value represents the mean \pm S.E.M obtained from eight animals. ${ }^{*} \mathrm{P}<0.01$, compared to the corresponding saline-treated group (Tukey's test). ( $\square$ ) control group, (G) 5,7-DHT-treated group.

\section{DISCUSSION}

Both monoamines and their metabolite levels (Table 1) and densities of $\left[{ }^{3} \mathrm{H}\right] 8-\mathrm{OH}-\mathrm{DPAT}$ binding (Fig. 1, Table 2) in the brain demonstrated that pretreatment with 5,7-DHT selectively destroyed 5-HT neurons and $5-\mathrm{HT}_{1 \mathrm{~A}}$ autoreceptors located on those cell bodies, without affecting postsynaptic $5-\mathrm{HT}_{1 \mathrm{~A}}$ receptors located on the postsynaptic neurons. This selective destruction of 5-HT ncurons with 5,7-DHT had no significant effect on the spontaneous drinking behaviors of the rats (Fig. 2). Also, the drinking behaviors of these 5,7-DHTtreated rats, like those of the control rats, are markedly suppressed by electric shock (Fig. 2). These results were in agreement with the data by Thiebot et al. (19) and Commissaris et al. (20), who reported no increase in the punished behavior of 5,7-DHT-treated rats in the Geller-Seifter conflict test and the Vogel conflict test, respectively. However, Tye et al. (21) have reported that the administration of 5,7-DHT into the ventromedial tegmentum produced anticonflict action in fooddeprived rats, and that the anxiolytic effects of benzodiazepines may result from a reduction in the activity of the serotonergic neuron system. On the other hand, in the studies of escape behavior after aversive electrical stimulation of the dorsal periaqueductal grey region of

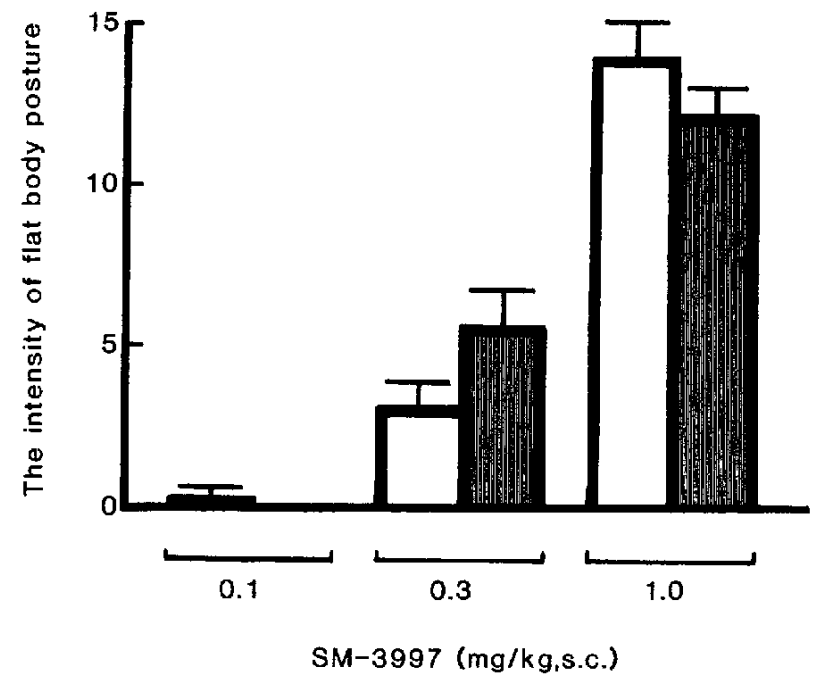

Fig. 4. The effects of the treatment with 5,7-DHT on flat body posture induced by tandospirone in rats. Tandospirone was administered 15 days following the intracerebroventricular injection of 5,7-DHT. Following the tandospirone administration, the intensities of a flat body posture were measured during a 30 -min period. Each value represents the mean \pm S.E.M. obtained from cight animals. ( $\square$ ) control group, (国) 5,7-DHT-treated group.

the brain, it has been reported that a reduction of 5-HT systems enhances the aversive response (22), and that 5-HT agonists containing 5-HT itself, in contrast, show antiaversive action (23). This discrepancy may be due to differences in the specificity or manner of approach that has been used either to reduce or to enhance serotonergic mechanisms, or differences in the methods used to estimate the anxiolytic activity. The results obtained in the present study suggest at least that a reduction in the activity of 5-HT neuron systems does not produce anxiolytic action in rats.

Tricklebank et al. (24) have reported that a flat body posture in rats is mediated by postsynaptic $5-\mathrm{HT}_{1 \mathrm{~A}}$ receptors. Tandospirone induced this behavior in 5,7DHT-treated rats as well as in control rats. Since 5,7DHT treatment had no significant effect on postsynaptic $5-\mathrm{HT}_{1 \wedge}$ receptors (Table 2 ), this is in agreement with the result reported by Tricklebank et al. Likcwise, the treatment with 5,7-DHT failed to alter the anticonflict activity of tandospirone in rats (Fig. 3). This suggests that the anticonflict action of tandospirone is not due to its effect on 5- $\mathrm{HT}_{1 \mathrm{~A}}$ autoreceptors located on 5HT neurons. Since we have presented the following evidence that tandospirone shows anticonflict action, at least in part, by binding to central $5-\mathrm{HT}_{1 \mathrm{~A}}$ receptors and activating them as agonists, these findings suggest that the anticonflict action of tandospirone may be mediated by postsynaptic 5-HT $\mathrm{T}_{1 \mathrm{~A}}$ receptors. That is: a) tandospirone binds selectively to central $5 \cdot-\mathrm{HT}_{1 \mathrm{~A}}$ recep- 
tors with high affinity $(7,8,11,12)$, b) tandospirone induces the "serotonin behavioral syndrome" (Fig. 4 of this paper and ref. 25), c) tandospirone reduces 5-HT turnover rate in the rat brain (15), d) tandospirone inhibits forskolin-stimulated adenylate cyclase activity in rat hippocampal membranes, and this effect is antagonized by a $5-\mathrm{HT}_{1 \mathrm{~A}}$ antagonist (26), e) the inhibition of hippocampal rhythmical slow activity by tandospirone is antagonized by a $5-\mathrm{HT}_{1 \mathrm{~A}}$ antagonist (27), and f) the anticonflict action of tandospirone is inhibited by a 5 $\mathrm{HT}_{1 \mathrm{~A}}$ antagonist (H. Shimizu et al, unpublished data).

This conclusion is also supported by the results reported by Kataoka et al. (28), who showed that the administration of tandospirone into the dorsal hippocampus produced a potent anticonflict action in rats, and Godbout et al. (29), who demonstrated that the sensitivity of the somatodendritic $5-\mathrm{HT}_{1 \mathrm{~A}}$ receptors was reduced by the sustained administration of tandospirone and that an augmented tonic activation of postsynaptic $5-\mathrm{HT}_{1 \mathrm{~A}}$ receptors would produce the anxiolytic effect. In regard to other $5-\mathrm{HT}_{1 \mathrm{~A}}$ receptor-related anxiolytics, it has been reported that buspirone and ipsapirone produced anxiolytic activity in raphe-lesioned animals (30) and in animals whose 5-HT neurons are destroyed by $p$ chloroamphetamine (31). Moreover, Kostowski et al. (32) have reported that the administration of buspirone into the hippocampus produced anxiolytic action in an elevated plus-maze test. On the other hand, there are also some reports suggesting the involvement of presynaptic $5-\mathrm{HT}_{1 \mathrm{~A}}$ receptors in the anxiolytic activity of these $5-\mathrm{HT}_{1 \mathrm{~A}}$ receptor-related anxiolytics. Namely, it has been reported that the anxiolytic effect of buspirone or gepirone was antagonized in 5,7-DHT-treated animals in a coflict test (33) and a two-compartment exploratory test (34). It also has been reported that the administration of buspirone and ipsapirone into the raphe nuclei produced anxiolytic actions in several animal models of anxiety $(34,35)$. The pharmacological profiles of buspirone and ipsapirone are not the same as that of tandospirone. Buspirone and ipsapirone, for example, show much higher $\mathrm{D}_{2^{-}}$and $\alpha_{1}$-antagonist activitics, respectively, than tandospirone (36). Moreover, intrinsic activities of buspirone and ipsapirone for 5$\mathrm{HT}_{1 \mathrm{~A}}$ receptors are lower than that of tandospirone $(\mathrm{H}$. Shimizu et al., unpublished data). Therefore, such different pharmacological properties of the $5-\mathrm{HT}_{1 \mathrm{~A}}$ receptor-related anxiolytics might lead to the abovementioned conflicting results. It is, however, difficult to compare these results because of the different experimental conditions used in these studies, so that the cause of these contradictory findings is not clear. Therefore, further studies are necessary to clarify which $5-\mathrm{HT}_{1 \mathrm{~A}}$ receptors mediate anxiolytic activity of the 5-
$\mathrm{HT}_{1 \mathrm{~A}}$ receptor-related anxiolytics. However, as far as tandospirone is concerned, the present results suggest the importance of postsynaptic $5-\mathrm{HT}_{1 \mathrm{~A}}$ receptors in its anxiolytic mechanism.

The brain region containing the highest density of postsynaptic 5-HT $1 \mathrm{~A}$ receptors has been shown to be the hippocampus (Table 2 of this paper and ref. 9), which has long been thought to be implicated in the control of anxiety. Gray (37) has reported that activated neuronal activity is observed in the hippocampus of anxious animals and that anxiolytics share the property of having inhibitory effects in the hippocampus. Our previous studies have shown that tandospirone inhibits neuronal activities in the rat hippocampus through postsynaptic $5-\mathrm{HT}_{1 \mathrm{~A}}$ receptors $(27,38)$. Moreover, as previously mentioned, the microinjection of tandospirone into the dorsal hippocampus produced the anticonflict action in rats (28). In the light of these findings, it is suggested that the agonist action of tandospirone on postsynaptic $5-\mathrm{HT}_{1 \mathrm{~A}}$ receptors, especially in the hippocampus, may produce its anxiolytic activity.

Acknowledgments

We thank Mrs. Y. Ueda and Miss S. Toma for their skillful assistance.

\section{REFERENCES}

1 Wise, C.E., Berger, B.D. and Stein, L.: Benzodiazepines: Anxiety-reducing activity by reduction of serotonin turnover in the brain. Science 177, 180-183 (1972)

2 Bradley, P.B., Engel, G., Feniuk, W., Fozard, J.R., Humphrey, P.P.A., Middlemiss, D.N. et al.: Proposals for the classification and nomenclature of functional receptors for 5 hydroxytryptamine. Neuropharmacology 25, 563 - 576 (1986)

3 Dumuis, A., Sebben, M. and Bockaert, J.: The gastrointestinal prokinetic benzamide derivatives are agonists at the nonclassical 5-HT receptor $\left(5-\mathrm{HT}_{4}\right.$ ) positively coupled to adenylate cyclase in neurons. Naunyn Schmiedebergs Arch. Pharmacol. 340, $403-410$ (1989)

4 Glennon, R.A.: Central serotonin receptors as targets for drug research. J. Med. Chem. 30, 1-12 (1987)

5 Herrick-Davis, K. and Titeler, M.: Detection and characterization of the serotonin 5-HT $1 \mathrm{D}$ receptors in rat and human brain. J. Neurochem. 50, 1624-1631 (1988)

6 Shimizu, H., Hirose, A., Tatsuno, T., Nakamura, M. and Katsube, J.: Pharmacological propertics of SM-3997: A new anxioselective anxiolytic candidate. Japan. J. Pharmacol. 45, $493-500(1987)$

7 Shimizu, H., Karai, N., Hirose, A., Tatsuno, T., Tanaka, H., Kumasaka, Y. and Nakamura, M.: Interaction of SM3997 with serotonin receptors in rat brain. Japan. J. Pharmacol. $46311-314$ (1988)

8 Shimizu, H., Tatsuno, T., Hirose, A., Tanaka, H., Kumasaka, Y. and Nakamura, M.: Characterization of the putative anxiolytic SM-3997 recognition sites in rat brain. Life Sci. 42, 
$2419-2427$ (1988)

9 Gozlan, H., El Mestikawy, S., Pichat, L., Glowinski, J. and Hamon, M.: Identification of presynaptic serotonin autoreceptors using a new ligand: ${ }^{3}$ H-PAT. Nature 305, 140-142 (1983)

10 Verge, D., Daval, G., Patey, A., Gozlan, H., El Mestikawy, S. and Hamon, M.: Presynaptic 5-HT autoreceptors on serotonergic cell bodies and/or dendrites but not terminals are of the 5-HT AA $_{\text {A }}$ subtype. Eur. J. Pharmacol. 113, 463-464 (1985)

11 Tanaka, H., Shimizu, H., Tatsuno, T., Hirose, A., Kumasaka, Y. and Nakamura, M.: Autoradiographic evidence for the interaction of SM-3997 with $5-\mathrm{HT}_{1 \mathrm{~A}}$ receptors in the rat brain. Japan. J. Pharmacol. 52, 504- 507 (1990)

12 Tanaka, H., Shimizu, H., Kumasaka, Y., Hirose, A., Tatsuno, T, and Nakamura, M.: Autoradiographic localization and pharmacological characterization of ${ }^{3} \mathrm{H}$-tandospirone binding sites in the rat brain. Brain Res. 546, $181-189$ (1991)

13 Gerson, S. and Baldessarini, R.: Selective destruction of serotonin terminals in rat forcbrain by high doses of 5,7dihydroxytryptamine. Brain Res. 85, 140-145 (1975)

14 Baumgarten, H.G., Klemm, H.P., Lachenmayer, L., Bjorklund, A., Lovenberg, W. and Schlossberger, H.G.: Mode and mechanism of action of neurotoxic indoleamines: A review and a progress report Ann. N.Y. Acad. Sci. 305, 3-24 (1978)

15 Tatsuno, T., Shimizu, H., Hirose, A., Tanaka, H., Kumasaka, Y. and Nakamura, M.: Effects of putative anxiolytic SM-3997 on central monoaminergic systems. Pharmacol. Biochem. Behav. 32, 1049-1055 (1989)

16 Verge, D., Daval, G., Marcinkiewicz, M., Patey, A., El Mestikawy, S., Gozlan, H. and Hamon, M.: Quantitative autoradiography of multiple $5-\mathrm{HT}$, receptor subtypes in the brain of control or 5,7-dihydroxytryptamine-treated rats. J. Neurosci. 6, $3474-3482$ (1986)

17 Lowry, O.H., Rosebrough, N.J., Farr, A.L. and Randall, R.J.: Protein measurement with the Folin Phenol reagent. J. Biol. Chem. 193, 265-275 (1951)

18 Vogel, J.R., Beer, B. and Clody, D.E.: A simple reliable conflict procedure for testing antianxiety agents. Psychopharmacology (Berlin) 21, 1 - 7 (1971)

19 Thiebot, M.H., Hamon, M. and Soubric, P.: Attenuation of induced anxiety in rats by chlordiazepoxide: Role of the raphe dorsalis benzodiazepine binding sites and serotonergic neurons. Neuroscience 7, 2287-2294 (1982)

20 Commissaris, R.L., Lyness, W.H. and Rech, R.H.: The effects of $\alpha$-lysergic acid diethylamide (LSD), 2,5-dimethoxy4-methylamphetamine (DOM), pentobarbital and methaqualone on punished responding in control and 5,7dihydroxytryptamine-treated rats. Pharmacol. Biochem. Behav. 14, 617-623 (1981)

21 Tye, N.C., Everitt, B.J. and Iversen, S.D.: 5-hydroxytryptamine and punishment. Nature 268, 741 - 743 (1977)

22 Kiser, R.S. and Lebovitz, R.M.: Monoaminergic mechanisms in aversive brain stimulation. Physiol. Behav. 15, 47- 53 (1975)

23 Graef, F.G.: The anti-aversive action of minor tranquilizers. Trends Pharmacol. Sci. 5, 230-233 (1984)

24 Tricklebank, M.D., Forler, C. and Fozard, J.R.: The involvement of subtypes of the $5-\mathrm{HT}_{1}$ receptor and of catecholaminergic systems in the behavioural response to 8-hydroxy-2(di-n-propylamino) tetralin in the rat. Eur. J. Pharmacol. 106, $271-282(1985)$
25 Shimizu, H., Hirose, A., Karai, N., Tatsuno, T., Nakamura, M. and Katsube, J.: The mechanism of the pharmacological action of SM-3997: A new anxioselective anxiolytic agent. Japan. J. Pharmacol. 40, Supp. 191P (1986)

26 Shimizu, H., Tatsuno, T., Hirose, A., Tanaka, H., Kumasaka, Y. and Nakamura, M.: The pharmacological properties of SM-3997: a comparative study with some 5-HT $1 \mathrm{~A}$ related anxiolytics. Japan. J. Pharmcol. 49, Supp. 227P (1989)

27 Hirose, A., Tsuji, R., Shimizu, H., Tatsuno, T., Tanaka, H., Kumasaka, Y. and Nakamura, M.: Inhibition by 8-hydroxy-2(di-n-propylamino) tetralin and SM-3997, a novel anxiolytic drug, of the hippocampal rhythmical slow activity mediated by 5-hydroxytryptamine-1A receptors. Naunyn Schmiedebergs Arch. Pharmacol. 341, 8-13 (1990)

28 Kataoka, Y., Shibata, K., Miyazaki, A., Inoue, Y., Tominaga, K., Koizumi, S. et al: Involvement of the dorsal hippocampus in mediation of the antianxiety action of tandospirone, a 5-hydroxytryptamine ${ }_{1 \mathrm{~A}}$ agonistic anxiolytic. Neuropharmacology 30, 475-480 (1991)

29 Godbout, R., Chaput, Y., Blier, P. and Montigny, C.: Tandospirone and its metabolite, 1-(2-pyrimidinyl)-piperazine 1. Effects of acute and long-term administration of tandospirone on serotonin neurotransmission. Neuropharmacology 30, $679-690(1991)$

30 Davis, M., Cassella, J. and Kehne, J.H.: Serotonin does not mediatc anxiolytic effect of buspirone in the fear-potentiated startle paradigm: comparison with 8-OH-DPAT and ipsapirone. Psychopharmacology (Berlin) 94, 14-20 (1988)

31 Chojnacka-Wojcik, E. and Przegalinski, E.: Evidence for the involvement of $5-\mathrm{HT}_{1 \mathrm{~A}}$ receptors in the anticonflict effect of ipsapirone in rats. Neuropharmacology 30, $703-709$ (1991)

32 Kostowski, W., Plaznik, A. and Stefanski, R.: Intrahippocampal buspirone in animal models of anxicty. Eur. J. Pharmacol. 168, 393-396 (1989)

33 Eison, A.S., Eison, M.S., Stanley, M. and Riblet, L.A.: Serotonergic mechanisms in the behavioral effect of buspirone and gepirone. Pharmacol. Biochem. Behav. 24, $701-707$ (1986)

34 Carli, M., Prontera, C. and Samanin, R.: Evidence that central 5-hydroxytryptaminergic neurones are involved in the anxiolytic activity of buspirone. Br. J. Pharmacol. 96, 829836 (1989)

35 Higgins, G.A., Bradbury, A.J., Jones, B.J. and Oakley, N.R.: Behavioural and biochemical consequences following

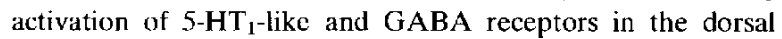
raphe nucleus of the rat. Neuropharmacology 27, 993-1001 (1988)

36 Nakamura, M., Shimizu, H., Tatsuno, T., Tanaka, Y., Kumasaka, Y. and Hirose, A.: The pharmacological profile of 5- $\mathrm{HT}_{1 \mathrm{~A}}$ related anxiolytics: Interaction with $5-\mathrm{HT}_{1 \mathrm{~A}}, \mathrm{D}_{2}$ and $\alpha_{1}$ receptors. Soc. Neurosci. Abs. 1233P (1989)

37 Gray, J.A.: The Neuropsychology of Anxiety: An Enquiry into the Functions of the Septo-Hippocampal System. Clarendon Press, Oxford (1982)

38 Hirose, A., Sasa, M., Akaike, A. and Takaori, S.: Inhibition of hippocampal $\mathrm{CA}_{1}$ neurons by 5-hydroxytryptamine, derived from the dorsal raphe nucleus and the 5-hydroxytryptamine $_{1 \mathrm{~A}}$ agonist SM-3997. Neuropharmacology 29, $93-$ $101(1990)$

39 Paxinos, G. and Watson, C.: The Rat Brain in Stereotaxic Coordinates. Academic Press, North Ryde (1986) 